\title{
Courir, bon pour le corps et pour l'esprit
}

\section{Jean Martin}

Dr med., membre de la rédaction

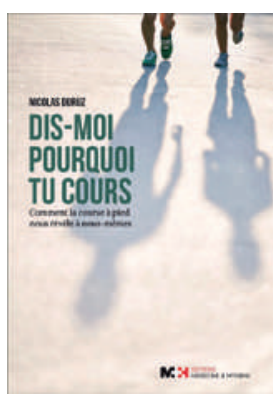

Nicolas Duruz

Dis-moi pourquoi

tu cours

Genève: Ed. Médecine et Hygiène; 2015.

117 pages. $15.00 \mathrm{CHF}$. ISBN 978-2-88049-396-7
Nicolas Duruz, psychologue et psychothérapeute, est professeur honoraire de l'Université de Lausanne. A près de soixante ans, il a découvert la course à pied et en est devenu un praticien engagé. Douze ans plus tard, il raconte ses expériences de coureur, cette description étant enrichie d'éléments tirés de ses compétences académiques. Ce petit ouvrage m'a vivement intéressé dans la mesure où, durant vingt-cinq ans, j'ai beaucoup couru, des courses de grand fond notamment. Et bien sûr, quand deux coureurs se rencontrent, la discussion est nourrie. Le vécu/ressenti qu'il décrit, que ce soit au plan psychologique ou physique, m'a beaucoup parlé.

Deux parties à l'ouvrage. La première décrit plusieurs «états du corps» que peuvent connaitre les coureurs de fond. La deuxième présente et discute une typologie de l'expérience de courir, en quatre types («différents styles d'être-au-monde qui caractérisent l'acte de courir»): contactuel, performant, collectif et motivé (l'auteur court contactuel, j'ai couru plutôt performant-collectif). Posée à un coureur à pied régulier, une question fréquente est «Mais qu'est-ce qui vous fait courir?». Pour se sentir vivre, améliorer sa forme physique, perdre du poids, aller au bout de soi-même? Duruz à ce sujet: "J'ai réalisé que j'en apprendrais sûrement davantage si je posais la question du 'Comment courez-vous?', si je cherchais à comprendre le pourquoi par le détour du comment.» C'est le propos du livre. Ci-dessous des pièces de son propre témoignage.

Sur les débuts. «M'extirper de mes activités professionnelles en cherchant à me changer les idées, voilà probablement ce à quoi j'aspirais. J'y ai pris goût, puisque douze ans plus tard je continue à courir, participant chaque année à six ou sept courses populaires.» «L'expérience de courir s'est progressivement invitée dans mon existence comme une métaphore du bien-vivre.»

La pratique et les pensées qu'elle suscite. "Je cherche à courir en ménageant et en respectant mon corps, cet ami qui me met en lien avec autrui et le monde. En courant, je cherche à découvrir et expérimenter le neuf de chaque instant [...], à accorder à chaque moment la place et l'intensité qu'il mérite, les vivre l'un après l'autre dans un certain lâcher prise.»
«Quand je cours, c'est toujours une grande fête pour les sens. Quel bonheur de découvrir à la fin de l'hiver les premières primevères. [...] Le paysage qui défile devant moi ne cesse de me solliciter, comme si j'étais assis dans un train, à ceci près qu'un corps en mouvement se trouve encore davantage stimulé.»

«Un autre vécu m’anime aussi lorsque j’aborde certaines pentes. Je me dis volontiers: Ici, 'c'est ici, là-bas, c'est là-bas', ou 'Maintenant, c'est maintenant; après, c'est après'. Je suis simplement ici, maintenant, avec le sentiment que le temps n'est ni trop long ni trop court.»

Le temps qu'on prend, qu'on se donne. "J'aime courir parce que c'est un moment où j'essaie de prendre du temps ... pour ne pas courir. Paradoxalement, je dis volontiers que c'est le moment où je cours le moins dans la vie. Quand je cours, je cherche à privilégier l'expérience du temps qui dure, sans souci premier d'un début et d'une fin.»

"Courir en vivant la durée constituée d'une succession de moments présents, tous réunis dans la répétition des mêmes gestes, voilà ce qui me convient. Courir en vivant une certaine routine plutôt qu'un perpétuel changement.

Des réflexions surviennent sur la vie qui s'écoule et sur la mort. "Je dois avouer que la pensée de gestes accomplis dans ma vie pour la dernière fois [y compris telle ou telle course] ne m'est pas étrangère. La perspective de devoir un jour tout arrêter, pour une raison ou une autre, se profile dans mon esprit. Comment puis-je l'accepter? Vais-je me contenter de mes beaux souvenirs? [...] Je sens bien au fond de moi que toutes ces rêvasseries sont nourries par des pensées sur la mort. Courir pour se sentir vivant jusqu'à la mort?»

Un ouvrage ramassé, facile et agréable à lire, qui intéressera toutes celles et ceux qui pratiquent le jogging ou le running avec une certaine régularité. Bien que ce ne soit pas un de ces manuels techniques avec plans d'entraînement et conseils nutritionnels ou de santé, il offre de multiples occasions de comparer sa propre expérience avec celle de Nicolas Duruz; ce qui a pour le lecteur une utilité pratique et contribue à cette convivialité/confraternité que vivent beaucoup d'adeptes de la course. 